for one relapse which passed away on returning to the same treatment.

CASE 5.-A woman, aged 40 years. The usual symptoms were well-marked, there was also considerable pigmentation of the skin and some glycosuria. She did not improve under this treatment but left in statu quo, except for diminution in the amount of sugar passed.

CASE 6. - A girl, aged nine years. All the symptoms were present in a moderate degree, except exophthalmos. The thyroid has become softer and smaller. The circumference of her neck diminished three-quarters of an inch and accentuation and increased frequency of the heart and tremor have disappeared under administration of rodagen.

CASE 7.-A woman, aged 36 years. There was marked improvement of all the symptoms, which were very severe, under this treatment.

CASE 8.-A woman, aged 30 years, a patient of a medical friend, was greatly relieved, all her symptoms improving when placed on one-drachm doses of rodagen thrice daily. She had previously had various other kinds of treatment without any benefit.

CASE 9.-A woman, aged 42 years, the same patient as Case 5, was readmitted into hospital in November, 1907. Pigmentation and glycosuria were still present. She was ordered half a draohm of rodagen every four hours-i.e., three drachms daily - but as she did not give evidence of much improvement five grains of thyroidectin were substituted on Dec. 22nd with marked benefit.

CASE 10.-A nurse, aged 27 years, to whom I have already referred under the heading of etiology. She had all the symptoms well developed when she was ordered five grains of thyroidectin thrice daily. She has greatly improved under this treatment. Her pulse-rate has fallen from 130 to about 90 per minute, the circumference of her neck has decreased $1_{\frac{1}{2}}$ inches-i.e., from 13 inches to $11_{\frac{1}{2}}$ inches-and the nervous tremors and exophthalmos are less marked. This is the patient whose Graves's disease is complicated by phthisis.

CASE 11. - A woman, aged 25 years, whom I saw in consultation with Dr. Gerald Wallace in April, 1907, had improved so much under the administration of thyroidectin that we gave her permission, after due consideration of the circumstances, to marry, though 12 months previously that had been quite out of the question owing to the grave symptoms present. She had gained in weight and lost her nervousness, \&c., under treatment. I have recently heard from Dr. Wallace that she has been married for several months and is in good health, the improvement being maintained,

CASE 12.--A woman, aged 17 years, sister of Case No. 16, always had a large thyroid. This increased considerably in size at puberty, which took place at 15 years of age, and she then developed definite symptoms of exophthalmic goitre. She has been under treatment with thyroidectin now for some months and has shown great improvement in all directions.

CASE 13.-A woman, aged 36 years, who was under the care of a medical friend for some years, manifested the classical symptoms, she gradually got worse until given rodagen one drachm thrice daily and then steadily improved.

CASE 14.-A man, aged 25 years, showed well-marked symptoms. He had improved on thyroidectin and been able to return to work. No other treatment was given.

All these cases I have mentioned have been under my observation since November, 1905, and I will not weary you with records of my earlier cases except to mention briefly two of special interest.

CASE 15. - A woman, aged 47 years, had had exophthalmos and other symptoms for more than 25 years. She was admitted into hospital in a very nervous condition; she had slight pyrexia, sweating, dyspnœea, and tachycardia. She died four days after admission with symptoms of heart failure and odema of the lungs.

CASE 16. - A woman, aged 30 years. This was a severe case; there was a two years' history; exophthalmos was very marked; her hair was turning white. She was in hospital for two months with some improvement when she developed an acute exacerbation of all the symptoms, with marked pyrexia, vomiting, delirium, coma, and death. Death being evidently due to a toxæmia. Progressive loss of weight, pyrexia, sweating, and diarrhoea are always bad signs.

I have not mentioned the various and numerous old methods of treatment of Graves's disease, it would take too long to discuss them. Anything which diminishes the action of the thyroid gland is beneficial, and it is probably in this way that local applications of ice and cold and the $x$ ray treatment act. I believe that in the anti-thyroid preparations we have valuable agents for counteracting the thyroidism of exophthalmic goitre; indeed, Case 1 was apparently saved from a fatal termination by the use of rodagen, Case 2 was cured, and the other cases show good results, and I believe better results will be obtained if larger doses than those I have mentioned are used. Where benefit is not obtained I consider that the dose is too small. Thus Dr. H. W. G. Mackenzie ${ }^{12}$ records an extremely severe case of Graves's disease which recovered from all the acute symptoms by taking one ounce of rodagen daily; and $\mathrm{Mr}$. Fidmunds ${ }^{13}$ has recently recorded three cases of marked improvement treated by the fresh milk obtained from thyroidectomised goats ( $1 \frac{1}{2}$ pints per diem). Heretofore I have never given more than one drachm of rodagen four times a day, as I remembered a case of Dr. G. R. Murray's in which bradycardia and collapse with a subnormal temperature occurred during prolonged treatment with drachm doses of rodagen, ${ }^{14}$ but in future $I$ shall, if necessary, give larger doses with caution. The only drawback to rodagen is its price. It costs about $3 s .6 d$. per ounce and on that account one feels inclined to prescribe it in small doses. Indeed, recently at the Stanley Hospital I have been trying thyroidectin instead, the good results obtained in Cases 9 and 10 encouraging me to do so.

I will not refer at any length to the value of operation in cases of Graves's disease. It appears to me to be a logical and scientific method of treatment except that we cannot be certain that compensatory hypertrophy will not take place in the portion of the gland left behind. Another patient had very marked symptoms, including nervous twitching, and was quite unfit for work. She was operated upon by my colleague, Mr. F. C. Larkin, who removed a considerable portion of one lobe of her thyroid. She was considerably relieved and is able to do her work with comfort. There is, however, not the slightest doubt that serious risk is entailed, patients not infrequently dying within 48 hours of the operation from sudden cardiac failure, as if from some poison gradually absorbed direct from the thyroid

The result of the treatment of these cases of Graves's disease with rodagen and thyroidectin will, I am sure, commend the adoption of anti-thyroid medication.

In conclusion, I would urge that when this treatment is being used a prolonged trial, with large doses if necessary, should be given, and careful observations and statistics of the condition of the patient should be noted, so that slight changes may be readily recognised. And I would impress upon the chemist the great importance of the most careful preparation and standardisation of these drugs.

Liverpool.

\section{SOME POINTS REGARDING SPINAL ANALGESIA, WITH A RECORD OF FIFTY CONSECUTIVE CASES.}

By J. MILL RENTON, M.B., Ch.B. GlasG., EX'IRA-DISPENSARY SURGEON, WESTERN INFIRMARY, GLASGOW.

AlThoUGH it is now fully ten years since spinal analgesia was first introduced there is still considerable difference of opinion as to the value of the method. The question of its relative safety as compared with general anæsthesia and the class of case for which it is best suited have still to be definitely settled. Most of those, however, who have had experience of the method feel that it has a definite sphere of usefulness and is one that has come to stay. The earlier records of unfavourable cases with accounts of the dangers connected with spinal analgesia have kept many from trying it at all. These dangers and bad results, however, are only those incidental to the introduction of any new method or

12 The Lancer, Feb. 1st, 1908, p. 393. 13 THE LANCET, Jan. 25th, 1908, p. 227. 
drug and with a better understanding of the procedure and an improved technique in carrying it out they have almost entirely disappeared. In this country Mr. A. E. Barker ${ }^{1}$ has done more than anyone else to place spinal analgesia on a sound and safe basis. He was the first to advocate the use of an injection compound of greater specific gravity than the cerebro-spinal fluid and to demonstrate that by the use of gravity and a study of the spinal curves a high analgesia could be obtained with perfect safety and regularity. In his method the rise in height of the analgesia is entirely due to his heavy compound travelling to the lowest point of the canal, usually somewhere about the upper dorsal region. There is not the least danger of any effect on the upper cervical region, as this is kept well elevated by raising the head and neck, and it must be apparent that it is impossible for his heavy fluid to travel upwards as it settles by mere weight at the lowest part of the canal. By using this heavy fluid one has definite control over the height of analgesia. Where one relies on the injection compound spreading upwards by diffusion or by shifting of the whole column of cerebro-spinal fluid one has no guarantee that once started upwards one will be able to control or limit it. Barker ${ }^{2}$ has now recorded over 200 cases treated by this method with most successful results and without any serious after-effects. Spencer and Houghton ${ }^{3}$ have likewise recorded 50 very successful cases. McGavin ${ }^{4}$ has recently published 50 cases done by the same method with excellent results. In the following 50 cases practically the same procedure as described by Barker has been adopted and his stovaine-glucose solution has been used throughout. I would like briefly to refer to a few of the more important points.

Position of the patient. - Careful attention to this is one of the most important factors in the success of the method. The patient lies on the side to be operated on with the head and neck well raised, except in hæmorrhoid and perineal cases, where the puncture is done in the sitting position. When lying the knees are fully flexed on the abdomen and held there by an assistant. If single-handed, the method of making the patient grasp his own legs and draw them upwards is a good one. Where a leg is injured as in fracture and cannot be drawn up properly I have found the flexing of one leg sufficient to enable the puncture to be performed. The head and neck are always carefully raised by means of pillows or a rest, thus insuring the safety of the cervical region. As regards elevation of the pelvis, there is no absolute rule, except that at most only a slight elevation, one or two inches, is necessary. It is important to have the patient in proper position with the head raised and the pelvis elevated before the puncture is done, so that as little movement as possible will be required after injection.

Puncture. - This can be done either between the third and fourth or second and third lumbar spines. When done here there is no danger of injuring the cord itself, as this terminates at the lower border of the first lumbar vertebra. The fourth lumbar spine is situated on a line joining the highest points of the iliac crests, so that the position for puncture is easily found. Speaking generally, where the highest analgesia is aimed at it should be done between the second and third spines. Occasionally, however, the interval between the second and third has felt so small and that between the third and fourth so much larger that $I$ have used the latter in preference, and have been quite successful in obtaining a high analgesia. Undoubtedly the puncture is most easily and satisfactorily performed absolutely in the middle line, and after a little practice there is little difficulty in entering the dural sac accurately in almost every case. A few exceptional cases may give rise to difficulty, as, for instance, one where the spines could not be felt at all, and where the whole lumbar spine seemed fixed in a forward curve. It was impossible in this case to get the needle in at all. It is important that the needle should be boiled in plain water and not in soda solution, as a trace of this renders the stovaine inactive. ${ }^{5}$ I found the nickel needles recommended by Barker to be most satisfactory in every way.

As a rule, from 2 to $2 \frac{1}{2}$ drachms of cerebro-spinal fluid

1 Barker: 'Brit. Med. Jour., March 23rd, 1907.

Ibid., Feb. 1st, 1908

3ov. 19th, 1907 . Houghton : Journal of the Royal Army Medical Corps, 4 McGavin: The Lancer, April 11th, 1908, p. 1058

Dean, Meeting of the British Medical Association, 1907. should be removed before injecting the analgesic compound. It is striking how in some patients the cerebro-spinal fluid spurts out and in others comes slowly, drop by drop. I have noticed that those cases where the cerebro-spinal tension seems high are more apt to have headache afterwards. It is consequently advisable to draw off rather more cerebro-spinal fluid from them. The compound used has been practically the same as Mr. Barker's and has been specially prepared in ampoules by John Macmillan, Limited, Glasgow : stovaine, 5 grains; glucose, 5 grains ; and sterilised water to 100 minims. 1 cubic centimetre $(17$ minims) is used each time, but as 2 minims remain in the needle one can only count on 15 minims of the solution reaching the canal-i.e., three-quarters of a grain, or about 5 centigrammes, of stovaine are injected. The dose has not been varied almost at all and the most severe abdominal operations have been performed with this dose. A few operations on the extremities have been done with a smaller dose. After injection the patient is gently rolled on to his back, the head and pelvis being kept in the same relative position, and in from five to ten minutes analgesia is usually quite complete and the patient ready for operation.

Height of analgesia. - I have endeavoured by a study of the spinal curves in individual patients to obtain a low analgesia when the operation was on the extremities and only a high analgesia when required. It is obviously unnecessary in operations on the extremities to obtain analgesia to the nipples, and in fact is undesirable, as nausea is more apt to occur with high analgesias. It must be remembered that the spinal curves vary somewhat in different people and also the size of the shoulders and pelvis has an effect on the level of the canal. Accordingly, it is sometimes necessary to modify slightly the procedure in individual cases. In operations on the extremities the puncture is usually made between the third and fourth spines without any elevation of the pelvis, and if thought desirable the shoulders are slightly raised, so that the analgesia does not usually spread higher than the umbilicus. Where a high analgesia is desired the shoulders rest on the table, the pelvis is elevated from 1 to 2 inches according to the case, and the puncture is made between the second and the third spines. It seems probable that analgesia spreads upwards more rapidly when the patient is in the lateral position, so it is consequently advisable to keep him on his side from one to two minutes before rolling him on to his back. As a rule the patient has been kept in the same position with the head raised and the pelvis slightly elevated throughout the entire operation, although recently I have been removing the pelvic pad when the analgesia was high enough. By carefully following out these details, slightly modified in individual cases, one can obtain analgesia to the sternum or nipples without the least danger. In no case has there been any difficulty with the breathing, even although analgesia has several times been noted from 1 to 2 inches above the nipples. The Trendelen. burg position has never been used and two inches have been the utmost amount of pelvic elevation. No morphine or scopolamine has been given previous to operation. A screen is placed between the patient and the field of operation so that he cannot see what is going on and everything is done as quietly as possible. It is most important that someone should engage the patient in conversation and keep his attention occupied during the operation. His head and neck should be kept raised while he is being removed from the theatre and he should be well propped up on his return to bed. It is hardly necessary to add that, of course, strict asepsis is essential to the safety of spinal analgesia. I have now carried out this method in 50 cases and have found it very satisfactory. From the following list it will be seen that it has been used in a large variety of surgical conditions.

The following is a summary of the abdominal cases: Appendix (quiescent), 9 cases; appendix (acute), 3 cases; laparotomy above umbilicus, 4 cases; intestinal obstruction, 3 cases ; and fæcal fistula of cæcum, 1 case ; total abdominal operations, 20 cases. The operations on other parts of the body comprised: Inguinal hernia, 6 cases; removal of testis, 5 cases ; removal of semilunar cartilage, 2 cases ; removal of renal calculi, 1 case; circumcision, 1 case; varicose veins, 2 cases; hæmorrhoids, 5 cases ; wiring patella, 1 case; plating fracture of tibia, 1 case; and suprapubic prostatectomy, 1 case. Failure to produce 
sufficient analgesia occurred in 3 cases and failure to puncture in 2 cases. I should like to refer in detail to a few of the more interesting of these cases.

CAsE 9.-The patient was a man, aged 39 years, who had received a blow over the left kidney. He was admitted with swelling in the kidney region and very severe hæmaturia. He was suffering from an attack of bronchitis and was therefore unsuitable for a general anæsthetic. Puncture was done with the patient on the left side with the pelvis slightly elevated, between the second and third spines. There was a brisk flow of cerebro-spinal fluid and two drachms were withdrawn. One cubic centimetre of solution was injected. The patient was kept on the left side for five minutes, when analgesia was two inches above the costal margin. He was then turned on to the right side and the operation was begun. Twelve stones were removed from the kidney and the patient had no pain at all during the operation which lasted 40 minutes. He had slight discomfort once in the epigastrium when one of the uppermost stones was being dragged out. The patient chatted freely during the operation and was greatly pleased. Paralysis of the legs lasted one and a half hours. He was very well the next day. There was no headache or sickness at all.

CASE 12.-The patient was a man, aged 52 years, with intestinal obstruction with fæcal vomiting of three days' duration. He was very feeble. The pelvis was slightly elevated; puncture was done between the second and third spines. There was a slow flow and only a few drops were withdrawn. One cubic centimetre of solution was injected. In five minutes analgesia was above the umbilicus and incision was made below the umbilicus. There was obstruction due to a malignant tumour, so a Paul's tube was inserted. The operation lasted 30 minutes and the patient was quite comfortable all the time. The pulse was very feeble at the start but was rather better after the operation. At the end analgesia was to the ensiform. The patient was very well the next day and there was no headache or sickness.

CASE 15. - The patient was a woman, aged 45 years, with malignant disease of the stomach causing pyloric obstruction. She was very feeble. The pulse was so weak that a general anæsthetic was thought unsafe. The pelvis was elevated two inches; puncture was done in the second and third space. There was a slow flow; one drachm was removed and one cubic centimetre of the solution was injected. In seven minutes there was complete analgesia to the ensiform and the abdomen was opened by an incision above the umbilicus. Disease was so extensive that a gastroenterostomy could not be done and the abdomen was closed. Throughout the operation, which lasted 20 minutes, the patient was quite comfortable, and so far as the analgesia was concerned a gastro-enterostomy could have been done. The pulse kept fairly good all through and she had neither sickness nor headache.

CAsE 33. - The patient was a man, aged 67 years (the oldest case), with hydro-hæmatocele and diseased testis. He had marked arterio-sclerosis. Puncture was done in the third and fourth space in the recumbent position. There was no elevation of the pelvis. There was a good flow and two drachms were withdrawn; one cubic centimetre was injected. In eight minutes there was complete analgesia up to two inches above the pubes. The whole mass was removed along with the testicle and the patient felt no pain at all. He was very well afterwards. There was no headache, sickness, or shock.

CASE 35.-The patient was a man, aged 41 years, with acute ruptured appendix. He was very ill and the abdomen was very rigid. Puncture was done in the second and third space; there was a brisk flow and two drachms were withdrawn; one cubic centimetre was injected. In ten minutes there was analgesia to the costal margin and the operation was begun. It was striking in this case to feel the rigidity of the muscles pass off and the abdomen become soft. There was no pain or discomfort during the operation, which lasted 35 minutes. At the end there was analgesia to the nipples. The patient was very well the next day. There was no sickness or headache.

CASE 36.--The patient was a man, aged 40 years, with oblique fracture of the right tibia. Puncture was done in the third and fourth space on the right side; there was a slow flow, one drachm being withdrawn; one cubic centimetre of the solution was injected. There was no elevation of the pelvis and the shoulders were slightly raised. In five minutes the operation was begun and the patient was quite comfortable while his fracture was plated together. The operation lasted 50 minutes. He was very well the next day and there was no headache or sickness. There was analgesia to the umbilicus.

CASE 47.- The patient was a man, aged 65 years, for suprapubic prostatectomy. Puncture was done in the third and fourth space. There was no clevation of the pelvis. There was a brisk flow, two drachms being withdrawn; one cubic centimetre was injected. In nine minutes there was complete analgesia to the umbilicus and the operation was begun. There was no pain or discomfort at all, not even when the prostate, a rather adherent one, was being separated. The operation lasted 20 minutes ant the patient was very well all through. He was very well the next day. There was no headache or sickness and no apparent shock.

Condition during operation. - If the stovaine has been properly given the patient has no pain at all during the operation and will chat away quite comfortably during the most painful procedures. In many cases tactile sensation remains and the patient can tell that lie is being touched although he has no pain. There has becn no anxiety from the analgesia during any of the operations. In only one case did the pulse become rather feeble. This was an appendectomy in a young man who was very nervous, and it so rapidly improved that $I$ think it was due to his mental condition. There has never been any respiratory tronble and no cases of faintness have occurred. Occasionally nausea and even sickness occur at the commencement of or during the operation. This is most apt to occur when a high analgesia has been obtained and in abdominal cases. It is undoubtedly in some cases due to nervousness, but in others. this will not explain it. Five of our cases have had some nausea and sickness during operation, but it has always passed off in from three to ten minutes and the operation has been proceeded with quite comfortably.

Abdominal cases.-Abdominal relaxation is perfect and no. straining can take place as the abdominal muscles are paralysed. It is striking in an acute abdominal condition with marked rigidity to feel the muscles gradually relax and become soft as the stovaine begins to act. Cutting of the peritonenm causes no discomfort, but traction on the bowel or peritoneum sometimes gives rise to discomfort in the epigastric region and a feeling of nausea. This is more apt to occur if the analgesia has not extended far above the seat of operation and it was more marked in our early cases. Later I found that if the analgesia extended to the midsternum this feeling was rarely complained of. One of our early appendectomies had to get a little chloroform during the separation of some dense adhesions, as it caused him so much discomfort in the epigastrium. Acute abdominal cases do extremely well and none of them have had any nausea, sickness, or headache. Four cases of laparotomy above the umbilicus have been done, and in all the analgesia was quite complete, no pain being felt at all. One cannot, however, rely on quite such a long analgesia as lower down.

Hemorrhoid and perineal cases.-Here the puncture is done in the sitting position and the effect of the heavy compound is well seen. Owing to its weight it runs down into. the sacral curve and one only gets analgesia of the perineal region, the legs and abdomen remaining unaffected, although by the end of the operation there may be some analgesia and loss of power in the legs. The patient is quite unconscious of the dilatation of his sphincter and his pulse is not affected at all.

Hernias.-Here spinal analgesia is most satisfactory, the relaxation of the muscles is perfect, and no pain or dis. comfort is felt.

Operations on the extremities. - The analgesia is easily got here and is absolutely perfect, even tactile sensation being often absent.

Failures. - Out of the 50 cases there have been two failures to puncture and three failures to get sufficient analgesia after apparent injection.

Failures to punoturo.-Case 20, a man, aged 62 years, already referred to, where the lumbar spines could not be felt at all; and Case 44, a woman, aged 25 years. After some trouble the needle appeared to pass in all right, but no cerebro-spinal fluid could be got. Puncture was tried in two different places with the same result.

Frilures to produce analgesia after injection.-Case 6, a 
man, aged 20 years. There was a troublesome puncture and bleeding; blood coming with cerebro-spinal fluid. The patient got analgesia up to one inch above the pubes, but as it was an appendix operation a general anæsthetic had to be given. Case 39 , a man, aged 25 years, with varicocele; there was an easy puncture and only a partial analgesia was obtained. The skin incision caused some pain and a general anæsthetic was necessary. Case 43, a man, aged 57 years. There was a troublesome puncture, blood coming with cerebro-spinal fluid. Absolutely no effect was produced. McGavin ${ }^{6}$ has also recorded three very similar cases where little or no effect was produced.

Three explanations of these failures have been offered: (1) inactive stovaine; (2) a failure to land the full dose within the spinal theca; and (3) insusceptibility of the patient. I feel convinced that the cause in cases such as the above is the fact that the compound has not been wholly landed within the dural sac, but has really been injected outside. It is possible for this accident to occur even though cerebro-spinal fluid has been got. By using Barker's fine cannula it is hardly possible for the injection to escape between the needle and the post layer of the dural sac unless the patient moves at the time of injection when the point might slip out. With a very lax sac, however, it is quite easy to puncture both layers of the sac and when injection is made for the whole or part of the compound to escape anteriorly. This is undoubtedly not common, but I suggest it as accounting for some of the cases where no effect has been produced. I had one other case where the injection caused absolutely no effect, and so convinced was I that the compound had not entered that I repunctured and again injected the full dose. 'I'his acted in absolutely the usual way. I was not able to give any of the three failures a second injection, but had it been done, failure might have been prevented. It is difficult to say whether the fact that blood came with the cerebro-spinal fluid and in one case continued to do so even after two drachms had been withdrawn, had anything to do with the failure. It is, of course, always a possibility that the stovaine may be inactive, but when freshly and carefully prepared this is not likely. Provided the full dose of active stovaine is injected accurately within the sac it is hardly conceivable that it should act on the nerves of one person and fail utterly to affect those of another. I feel that the explanation of idiosyncrasy is only to be accepted when all others fail. Where the analgesia cannot be got to rise it is always possible that some of the heavy compound has run down into the sacral curve and got imprisoned there. While these failures are undoubtedly flaws in the method I feel that they are all preventable and with increased skill and experience will not occur at all.

Length of anaigesia.-The longest operation performed was a frcal fistula of the croum which lasted 80 minutes. Analgesia to a needle has been noted in the legs as long as two hours after injection. Generally speaking, however, analgesia from 50 to 90 minutes can be relied on, with rather a shorter period for the epigastric region.

After-effects.-No bad results of any kind have developed afterwards which could be traced to the analgesia. Headache and sickness are occasional sequelæ but have not been marked in our series. 35 of the cases have had absolutely no headache or sickness. Five cases, mostly nervous patients, have been troubled with sickness and five have had some headache which, however, has always been controlled by aspirin or phenacetin. It is to be noted that none of the acute abdominal cases have had the least trace of headache, nausea, or sickness. The paralysis of the legs has always passed off completely in from one and a half to three hours, and no prolonged or permanent paralysis has been seen. There has never been any trace of meningeal irritation. One case was operated on twice with stovaine, and at the second operation, five days after the first, the cerebro-spinal fluid was found quite normal. Paralysis of the external rectus of the eye, which has been recorded, ${ }^{7}$ has not been seen in any of the cases. Retention of urine does not seem to be more marked after using spinal analgesia. As a matter of fact, most of the hernias and abdominal cases passed urine themselves. Tympanites has been present next day in a certain number of the cases but never to any marked extent. As many as possible of the cases have been examined a month

6 Loc. cit.
7 Torrance: Surgery, Gynæcology, and Obstetrics, December, 1907. or si
well.

Shock.-C'The question whether spinal analgesia prevents shock is one of the greatest importance and has been urged as one of its chief advantages. Dean, ${ }^{8}$ who has drawn special attention to this aspect of the subject, is of the opinion that it is the method par excellence in acute abdominal cases where shock is feared. One of our abdominal cases, an operation on the stomach and transverse colon of 80 minutes' duration, undoubtedly suffered from shock three hours later, but in her case the analgesia had passed off before the end of the operation and some chloroform was required for closing the abdominal wall. None of the other cases have shown any signs of shock and everyone has been struck with how satisfactory the method is in weakly patients and in acute abdominal conditions. It is also striking that such procedures as dilatation of the sphincter, ligature and division of the cord, division of the foreskin and division of the peritoneum not only give rise to no pain but do not affect the pulse in the slightest degree.

Conclusions. - In ordinary healthy people it comes to be a matter of choice whether spinal analgesia is used or not. Those who have a dread of general anasthesia will, as a rule, choose spinal analgesia, and there now seems no reason why they should not have the benefit of it. Nervous patients, on the other hand, will usually prefer general anæsthesia. It is, however, when an operation has to be performed on a patient unsuited for general anæesthesia that the great advantage of the method is seen. When properly used it has no bad effect on the heart or lungs, and is therefore much safer in some cases. I have also been struck with how well suited it is for certain types of cases which are unfavourable for general anæsthesia, such as old people with arterio-sclerosis, weak, feeble patients, and those suffering from certain acute abdominal conditions. Alcoholics who are notoriously troublesome to anæesthetise do excellently well with spinal analgesia. Tuffier $^{9}$ also points out that it can often be safely used where an operation has had to be abandoned on account of anxiety with the anæsthetic and records two cases of this nature. In our own series we have had two cases (a frcal fistula and a hæmorrhoid case) where the patients took the anæsthetic so badly that it was discontinued. They were both operated on next day under stovaine without any anxiety.

From a study of the recorded cases and from my own experience of this method I feel that it can now compare favourably in point of safety with general anxsthesia. Moreover, I think there is little doubt that in a fair number of surgical conditions it is the safer and better method and its use gives the patient an increased chance of recovery. At the same time it must be clearly understood that a careful study of the subject and the utmost care in carrying it out are necessary to insure its success and safety. Dr. J. Crawford Renton has operated on the majority of the cases and has been much pleased both with the analgesia and with the condition of the patients after operation. I am indebted to him for opportunities of carrying out this method. I would also like to thank his house surgeons, Dr. T. P. Grant and Dr. H. M. Grainger, for their assistance. Glasgow.

\section{AN APPLICATION OF OPSONIC METHODS IN COMPARING HUMAN AND BOVINE TUBERCULOSIS.}

\section{By F. L. POChIN, M.D., C.M. Edin., D.P.H. СаMв.}

UNTIL 1901 it was generally thought that tuberculosis in animals and man was one and the same disease. In that year, however, Koch created a sensation among those assembled at the British Congress on.Tuberculosis by stating that, in his opinion, human tuberculosis differed from bovine and cannot be transmitted to cattle. Further, he maintained that bovine tuberculosis is scarcely, if at all, transmissible to man. ${ }^{1}$ His opinion, it will be remembered, was arrived at as the result of the following experiments. 1. Six bovines were fed for seven months with food mixed with sputum 